\title{
Germinação de sementes de Canavalia rosea (Sw.) DC. (fabaceae) em diferentes substratos
}

A espécie Canavalia rosea (Sw.) DC., leguminosa pertencente à família Fabaceae, também conhecida como feijão-de-praia, compõe um ecossistema denominado jundu, que consiste numa vegetação de restinga composta por diferentes espécies. Esse trabalho teve como objetivo analisar a germinação de sementes de $C$ rosea sob diferentes tratamentos, cujas mudas são comumente utilizadas na recomposição do jundu na Praia do Massaguaçu, município de Caraguatatuba, SP. As sementes foram submetidas a oito tratamentos distintos, com proporções diferentes de areia da praia e terra vegetal, combinadas ou não com fertilizante (NPK 10-10-10). Também foi verificada se há influência do capim exótico presente na praia na germinação das sementes. Concluiu-se que o extrato do capim não interferiu na germinação das sementes, o que indica que essa espécie de capim não apresentou efeito alelopático sobre a C. rosea. Os substratos com maior proporção de areia em relação à terra vegetal, e que não continham fertilizante, foram mais adequados para a germinação das sementes e desenvolvimento da $C$. rosea. Esses resultados poderão contribuir para reduzir o custo da recomposição do jundu na Praia do Massaguaçu, pois constatou-se que a terra vegetal e o fertilizante são dispensáveis para a produção de mudas de C. rosea.

Palavras-chave: Feijão-de-praia; Jundu; Restinga.

\section{Germination of Canavalia rosea (Sw.) DC seeds. (fabaceae) on different substrates}

\begin{abstract}
Canavalia rosea (Sw.) DC. is a leguminous species which belongs to Fabaceae family, known as beach bean, and composes part of the coastal vegetation ecosystem called Jundu. This paper analyzed the germination of C. rosea seeds under different treatments. The seedlings of this species is used to recover the Jundu ecosystem of Massaguaçu Beach, in Caraguatatuba, northern coastline of the State of Sao Paulo. The seeds had eight different treatments, with different proportions of sand and clay, combined with fertilizer or not (NPK 10-10-10). It was also verified if there is influence of exotic grassy, presents on the beach, in the seeds germination. We concluded that the grassy did not interfere in the seeds germination. The substrates with more proportion of sand then clay and without fertilizer, were better to seeds germination and development of $\mathrm{C}$. rosea. These results may contribute to reduce the cost to recover the Jundu ecosystem of Massaguaçu Beach, considering that clay and fertilizer would not be necessary for the seedlings germination of $C$. rosea.
\end{abstract}

Keywords: Beach Beans; Jundu; Coastal Ecosystems.

Topic: Conservação da Biodiversidade

Reviewed anonymously in the process of blind peer.
Received: $10 / 12 / 2019$

Approved: $20 / 02 / 2020$
Gabrielle Bratti

Instituto Federal de São Paulo, Brasil

gabybratti@hotmail.com

\section{Samara Salamene}

Instituto Federal de São Paulo, Brasil

http://lattes.cnpq.br/3262036650536544

salamene@ifsp.edu.br

Mariana Médice Firme Sá

Universidade Federal de Viçosa, Brasil

http://lattes.cnpq.br/4164740177312753

http://orcid.org/0000-0001-6782-909X

mariana medice@hotmail.com
Allana Santos Belline de Vasconcelos

Instituto Federal de São Paulo, Brasil

allana28belline@gmail.com

\section{Nataly Rodrigues Martins}

Instituto Federal de São Paulo, Brasil

nataly.martins005@gmail.com

Thaís Verginio Costa

Instituto Federal de São Paulo, Brasil

tverginio13@gmail.com
Shananda Rosa Raffi

Instituto Federal de São Paulo, Brasil

shananda raffi@hotmail.com
Referencing this:

BRATTI, G.; SALAMENE, S.; SÁ, M. M. F.; VASCONCELOS, A. S. B.; MARTINS, N. R.; COSTA, T. V.; RAFFI, S. R.. Germinação de sementes de Canavalia rosea (Sw.) DC. (fabaceae) em diferentes substratos. Nature and Conservation, v.13, n.1, p.1-7, 2020. DOI: http://doi.org/10.6008/CBPC2318-2881.2020.001.0001 


\section{INTRODUÇÃO}

O jundu pode ser chamado de nhundu ou inhuntu, é uma vegetação nativo-litorânea formada por gramíneas e arbustos com uma rede de raízes profundas que seguram os grãos de areia (LIMA, 2001). Tem como função reter a areia que é levada pelo vento ou mar e, principalmente, evitar erosões. Não havendo esse tipo de vegetação, a erosão ocorre de forma mais acelerada, prejudicando as construções mais próximas ao mar e até a mesmo a natureza. Tem um papel importante no equilíbrio ambiental do local, e é essencial para preservação da biodiversidade e estabilização da areia (ITANHAÉM, 2015).

A Canavalia rosea (Sw.) DC., conhecida popularmente como feijão-da-praia, pertence à família Fabaceae e é uma das espécies pioneiras do jundu. Essa espécie está sob constante influência da salinidade, sobretudo nos períodos de maré alta quando as ondas se aproximam da formação psamófila-reptante, na qual ela está inserida, expondo-a ao contato direto com a água salgada (JEFFERIES et al., 1979, citado por COSTA et al., 2013). Essa espécie tem importância no que concerne a retenção do substrato da região praiana, exposta a forte ação eólica, principal agente modificador da paisagem litorânea (COSTA et al., 2013).

O presente trabalho teve como objetivo avaliar a germinação da semente de feijão-de-praia em oito tratamentos, bem como analisar o possível efeito alelopático de um capim exótico presente na Praia do Massaguaçu sobre a C. rosea, espécie utilizada para recomposição do jundu nessa praia, localizada em Caraguatatuba, litoral norte de São Paulo.

\section{MATERIAIS E MÉTODOS}

\section{Descrição da espécie}

A Canavalia rosea (Figura 1) pertence à família das Leguminosas (Fabaceae), uma das maiores famílias do reino vegetal. A espécie de $C$. rosea também é conhecida como feijão-de-praia, classificada como uma planta herbácea trepadeira. Contem caules rastejantes e subterrâneos com maior fixação ao substrato arenoso e consegue impedir a movimentação da areia, contribuindo assim, para que se tenha uma diminuição na erosão do solo (KREÜCH, 2003).

As principais características da espécie são listadas a seguir, conforme Queiroz et al. (2015): Caule: ramo rastejante; Folha: folíolo orbicular/obovado; ápice do folíolo arredondado/emarginado; Inflorescência: posição axilar; Flor: cor das pétalas rosa; Fruto: legume lateralmente compresso/túrgido; Semente: forma elipsoide, cor castanha.

Essa espécie está sob constante influência da salinidade, sobretudo nos períodos de maré alta quando as ondas se aproximam da formação psamófila-reptante (ou seja, que cresce em solos arenosos e são rastejantes), na qual ela está inserida, expondo-a ao contato direto com a água salgada (JEFFERIES et al., 1979, citado por LOURENÇO-JUNIOR et al., 2009). 


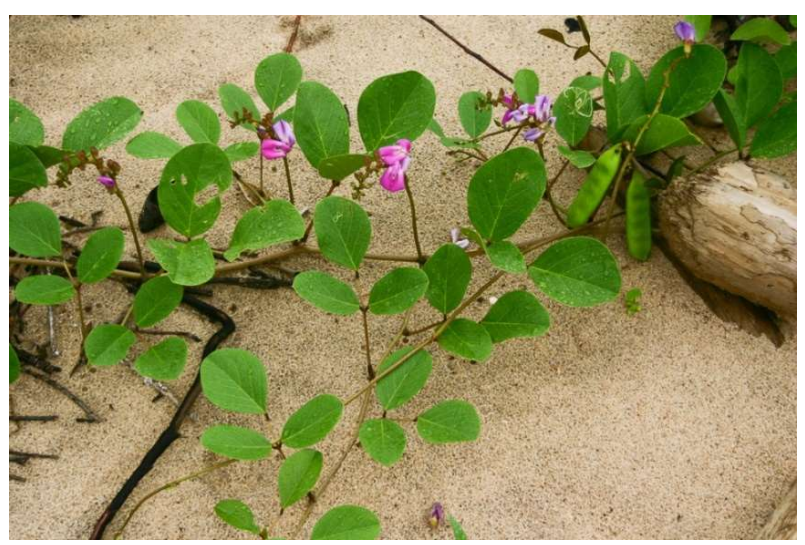

Figura 1: Canavalia rosea (Sw.) DC.

\section{Tratamentos das sementes}

Para a realização dos testes de germinação das sementes de $C$. rosea foram utilizados os materiais descritos na Tabela 1. As sementes foram plantadas em copos descartáveis devidamente identificados de acordo com a composição do substrato (Figura 2 e Tabela 2).

Tabela 1: Materiais utilizados para teste de germinação de sementes de Canavalia rósea.

\begin{tabular}{|l|l|}
\hline Material & Quantidade \\
\hline Sementes de Canavalia rosea & 64 \\
\hline Copo descartável $(400 \mathrm{ml})$ & 32 \\
\hline Recipiente plástico $(1000 \mathrm{ml})$ & 4 \\
\hline Fertilizante NPK 10-10-10 & $16 \mathrm{~g}$ \\
\hline Areia de praia & $5,8 \mathrm{~kg}$ \\
\hline Terra vegetal & $1,52 \mathrm{~kg}$ \\
\hline Pá de jardim & 1 \\
\hline Caneta permanente & 1 \\
\hline Béquer $(50 \mathrm{ml})$ & 2 \\
\hline Proveta (100 ml) & 1 \\
\hline Proveta $(500 \mathrm{ml})$ & 3 \\
\hline Balança & 1 \\
\hline Almofariz com pistilo & 1 \\
\hline
\end{tabular}

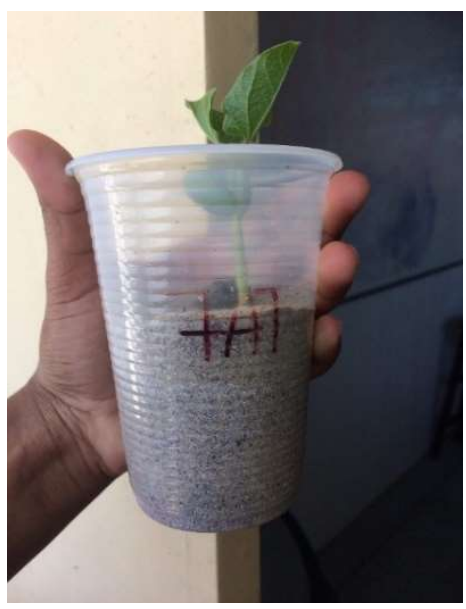

Figura 2: Sigla 7AT que significa que o substrato contem sete partes de areia e uma parte de terra.

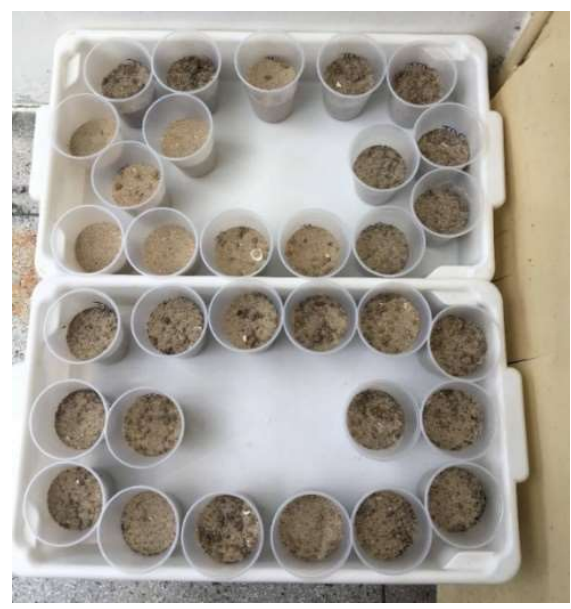

Figura 3: Experimento colocado nas bandejas.

O volume (em $\mathrm{ml}$ ) de areia e terra foi medido utilizando uma proveta. O conteúdo foi misturado e transferido para o copo. Nos tratamentos que continham NPK 10-10-10 (10\% de nitrogênio, 10\% de fósforo e $10 \%$ de potássio), a quantidade aplicada de fertilizante foi medida na balança. Por fim, foi introduzida a semente no copo com o substrato, na profundidade aproximada de $1 \mathrm{~cm}$. 0 experimento foi montado no dia 
06/04/2018. Após o plantio das sementes, os copos foram organizados em bandejas (Figura 3), colocadas em local arejado e com sombra. A germinação das sementes e o desenvolvimento das mudas foram acompanhados no período de 34 dias (de 06/04 a 09/05/2018).

Tabela 2: Composição dos substratos para germinação de sementes de Canavalia rosea

\begin{tabular}{|l|l|l|l|}
\hline \multirow{2}{*}{ Siglas } & Tratamento & \multicolumn{2}{|l|}{} \\
\cline { 2 - 4 } & Areia $(\mathbf{m l})$ & - & Ferra $(\mathbf{m l})$ \\
\hline A & 200 & - & - \\
\hline AF & 200 & 50 & 1,5 \\
\hline $3 A T$ & 150 & 50 & - \\
\hline 3ATF & 150 & 40 & 1,5 \\
\hline 5AT & 200 & 40 & - \\
\hline 5ATF & 200 & 25 & 1,5 \\
\hline 7AT & 175 & 25 & - \\
\hline 7ATF & 175 & & 1,5 \\
\hline
\end{tabular}

Nota: $A=$ areia; $T=$ terra; $F=$ fertilizante.

\section{Teste de alelopatia do capim}

Foi observado em campo que o capim presente na Praia do Massaguaçu afetou o desenvolvimento do jundu. Por isso, foi realizado um experimento para testar se o capim apresenta algum efeito alelopático sobre as sementes de $C$. rosea. O delineamento do experimento foi descrito na Tabela 3. Foi utilizada a proporção de três partes de areia para uma parte de terra, pois essa medida foi testada em outro trabalho e mostrou-se eficaz (NUNES et al., 2016). Oito sementes de $C$. rosea foram plantadas em recipiente plástico de 1 litro contendo $450 \mathrm{ml}$ de areia e $150 \mathrm{ml}$ de terra (Figura 4a).

O capim foi coletado na praia e macerado no almofariz com pistilo (Figura 4b). Foi acrescentado um pouco de água destilada para facilitar o processo de maceração do capim. No total, foram utilizados 4 vasilhames de 1 litro com oito sementes cada. Destes, em dois foram adicionados $30 \mathrm{ml}$ de extrato de capim (Figura 4c).

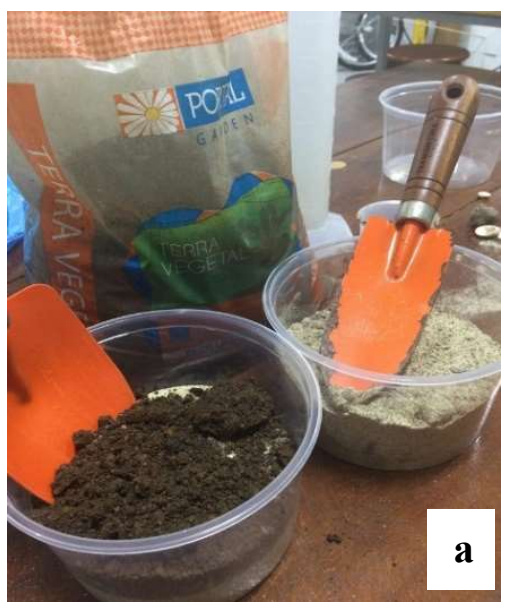

Figura 4. a) Mistura da terra vegetal com
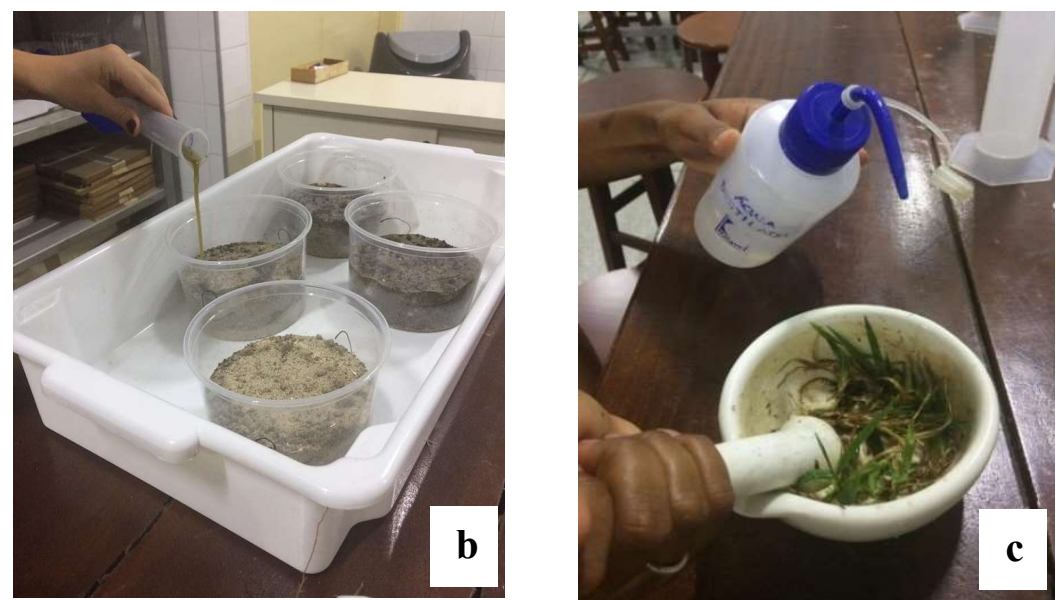

c

\section{adição do extrato de capim no plantio.}

\section{RESULTADOS E DISCUSSÃO}

Ao analisar o desenvolvimento das plantas, foi possível notar que a taxa de germinação das sementes foi de $40 \%$, ou seja, das 32 sementes plantadas, apenas 13 germinaram no período de avaliação (Tabela 3 ). 
Após uma semana, a primeira muda que se formou foi uma do tratamento 7AT, que continha sete partes de areia para uma parte de terra (Figura 5a). Na segunda semana, germinou uma das sementes do tratamento A, que continha somente areia da praia (Figura 5b). Assim, pode-se constatar que a espécie de Canavalia rosea, se desenvolveu mais rápido no substrato composto por maior quantidade de areia, o que corrobora a afirmação de Lourenço-Junior et al. (2009) de que essa espécie é psamófila.

Segundo Almeida-Junior et al. (2009), esse tipo de planta se estabelece na linha de praia compondo uma vegetação adaptada às condições salinas (halófila) e arenosas (psamófila) sob influências de marés, que contem espécies herbáceas reptantes que apresentam sistemas radiculares amplos e que delimita formações vegetais com outros blocos de plantas, conforme o distanciamento do mar.

Tabela 3: Quantidade de sementes que germinaram por tempo decorrido (em dias).

\begin{tabular}{|c|c|c|c|c|c|}
\hline \multirow[t]{2}{*}{ Tratamento } & \multicolumn{5}{|c|}{ Tempo (dias) } \\
\hline & 07 & 11 & 17 & 23 & 28 \\
\hline A & & 1 & 2 & & \\
\hline \multicolumn{6}{|l|}{$\mathrm{AF}$} \\
\hline 3 AT & & & & 1 & \\
\hline \multicolumn{6}{|l|}{3 ATF } \\
\hline 5 AT & & & 2 & 1 & \\
\hline 5 ATF & & & 1 & & 1 \\
\hline $7 \mathrm{AT}$ & 1 & 1 & & 1 & \\
\hline 7 ATF & & & & 1 & \\
\hline
\end{tabular}

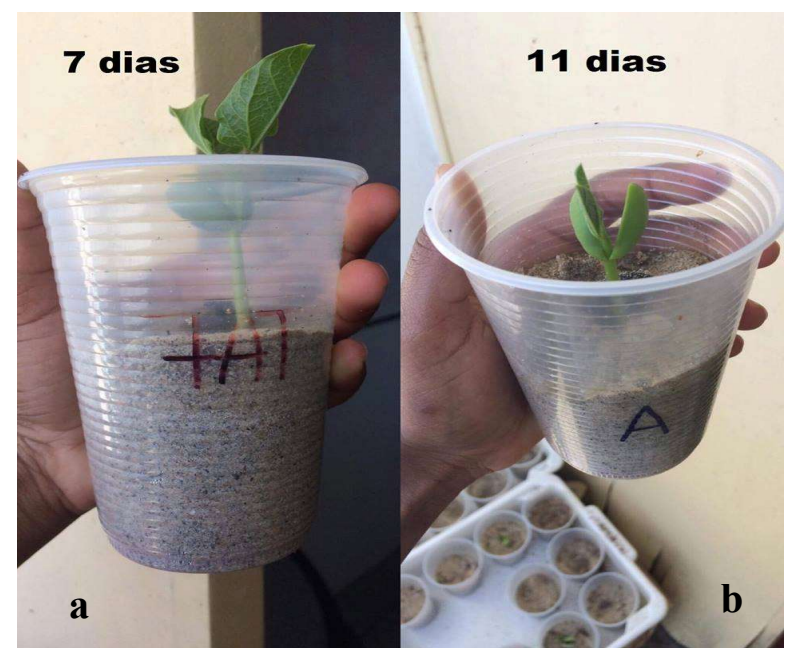

Figura 5: Desenvolvimento das primeiras mudas no tratamento com sete partes de areia para uma parte de terra (a) e somente areia da praia (b).

A partir da observação do desenvolvimento das sementes foi possível notar que ocorreu um atraso na germinação onde o substrato continha fertilizante (Figura 6). O uso do NPK pode ocasionar maior salinização no solo e intoxicar as plantas. A formulação adequada de NPK para plantas em desenvolvimento é 4-14-8, geralmente usado quando a espécie produz flores e frutos. Isso ocorre porque a planta em desenvolvimento precisa de uma quantidade maior de fósforo e a formulação 4-14-8 contém 14\% de fósforo (P), 4\% de nitrogênio (N) e 8\% de potássio (K). A formulação NPK 10-10-10 é mais eficaz para as plantas adultas. 


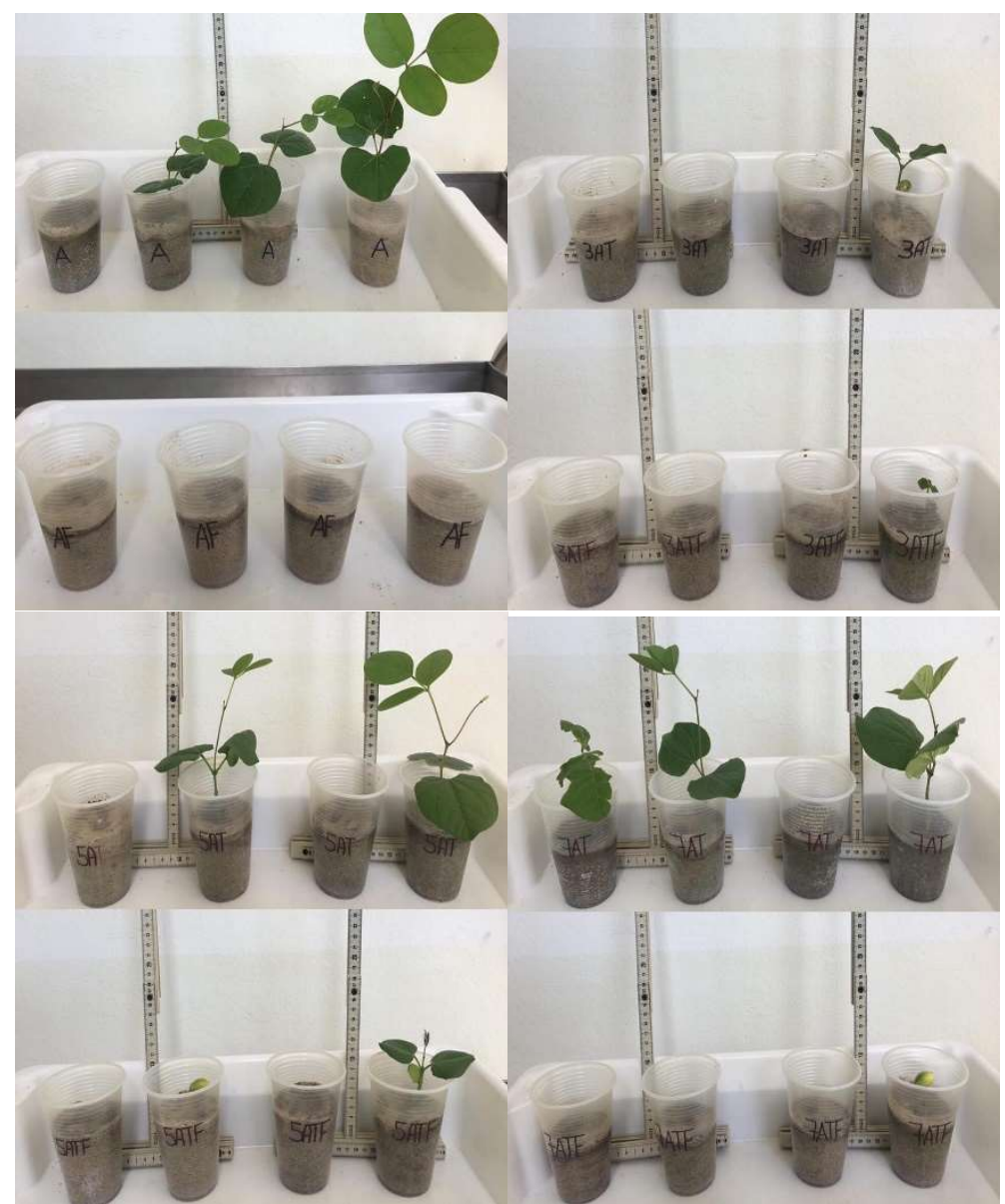

Figura 6: Crescimento de Canavalia rosea após 34 dias do plantio das sementes em diferentes substratos.

Quanto ao resultado da germinação das sementes submetidas ao substrato com o extrato de capim, não houve interferência no crescimento das mudas. Isso ocorreu porque, provavelmente, o capim não produz substância química com efeito alelopático sobre a C. rosea (Figura 7). Portanto, pode haver uma interferência física do capim sobre o jundu, onde as raízes podem estar impedindo o feijão-de-praia de se desenvolver adequadamente, ou essas duas espécies podem estar em competindo por nutrientes.

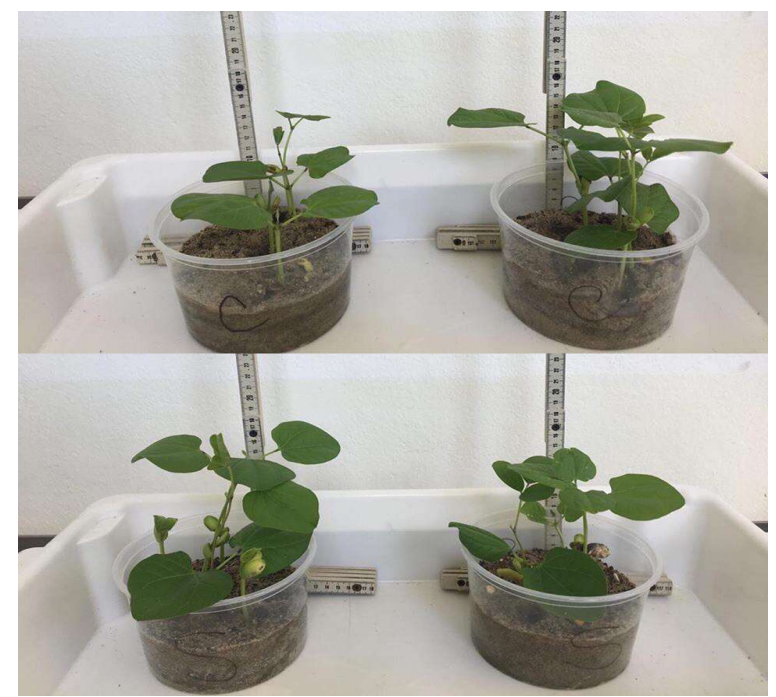

Figura 7: Mudas de C. rosea em substratos com (C) e sem (S) extrato de capim.

\section{CONCLUSÕES}

Concluiu-se, a partir do acompanhamento do plantio das sementes de C. rosea, espécie que compõe 
o jundu, que essa planta se desenvolveu melhor onde o substrato continha mais areia. O fertilizante utilizado no tratamento não foi eficaz para a germinação. Mesmo com o crescimento de poucas mudas, os resultados aqui obtidos foram de grande importância para contribuir com a recomposição da vegetação nativa litorânea, uma vez que o gasto necessário para produção de mudas poderá ter uma redução significativa. Futuros trabalhos que utilizem outros tratamentos para germinação das sementes e estudem com mais profundidade o efeito do capim exótico, poderão acrescentar informações que auxiliem na recuperação do jundu na Praia do Massaguaçu, fundamental para contenção da erosão costeira.

\section{REFERÊNCIAS}

ALMEIDA-JUNIOR, E. B.; ZICKEL, C. S.. Fisionomia psamófilareptante: riqueza e composição de espécies na Praia da Pipa, Rio Grande do Norte, Brasil. Pesquisas, Botânica, São Leopoldo, n.60, p.289-299, 2009.

COSTA, T. S.; AOYAMA, E. M.; FALQUETO, A. R.. Superação de dormência e salinidade na germinação de sementes e vigor de plântulas de Canavalia rosea (Sw.) DC. - Fabaceae. Revista de Ciências Agro-Ambientais, Alta Floresta, v.11, n.1, p.77-87, 2013.

ITANHAÉM. Vegetação rasteira ajuda a manter equilíbrio da região costeira. Itanhaém, 2015.

JEFFERIES, R. L.; DAVY, A. J.. Ecological processes in coastal environments. Oxford: Blackwell Scientific Publications, 1979.

KREÜCH, D.. Estudo fitoquímico e biológico de canavalia rósea. Monografia (Graduação em Química) - Universidade Federal de Santa Catarina, Florianópolis, 2003.
LIMA, A.. Aspectos jurídicos da proteção da Mata Atlântica. São Paulo: Instituto Socioambiental, 2001.

LOURENÇO-JUNIOR, J.; CUZZUOL, G. R. F.. Caracterização de solos de duas formações de restinga e sua influência na constituição química foliar de Passiflora mucronata Lam. (Passifloraceae) e Canavalia rosea (Sw.) DC. (Fabaceae). Acta Bot. Bras., São Paulo, v.23, n.1, 2009.

NUNES, A. F.; SANTOS, E. G. S.; SILVA, M. R. M.; SANTOS, V. A. L; SALAMENE, S.. Análise e Aplicação dos meios adotados para a contenção dos processos erosivos em Caraguatatuba. Monografia (Técnico em Meio Ambiente) Instituto Federal de Educação, Ciência e Tecnologia de São Paulo, Caraguatatuba, 2016.

QUEIROZ, L. P.; SNAK, C.. Canavalia in Lista de Espécies da Flora do Brasil: Jardim Botânico do Rio de Janeiro. JBRJ, 2015.

A CBPC - Companhia Brasileira de Produção Científica (CNPJ: 11.221.422/0001-03) detém os direitos materiais desta publicação. Os direitos referem-se à publicação do trabalho em qualquer parte do mundo, incluindo os direitos às renovações, expansões e disseminações da contribuição, bem como outros direitos subsidiários. Todos os trabalhos publicados eletronicamente poderão posteriormente ser publicados em coletâneas impressas sob coordenação da Sustenere Publishing, da Companhia Brasileira de Produção Científica e seus parceiros autorizados. Os (as) autores (as) preservam os direitos autorais, mas não têm permissão para a publicação da contribuição em outro meio, impresso ou digital, em português ou em tradução. 